\title{
Self-Reported Perceptions of Online Learning and Observed Online Learning Behaviors: To What Extent Are They Consistent?
}

Feifei Han

Office of Pro-Vice-Chancellor (Arts, Education and Law), Griffith Institute for Educational Research, Griffith University

\section{Correspondence:}

Feifei Han, Office of Pro-Vice-Chancellor (Arts, Education and Law) Griffith Institute for Educational Research Griffith University, Brisbane, Australia Email: feifei.han [at] griffith.edu.au

Keywords: perceptions of online learning, observed online learning behaviors, engineering students, Australian higher education

\begin{abstract}
This study investigates to what extent there is an association between students' self-reported perceptions of online learning and observed online learning behaviors recorded by the learning analytic data. The participants were 319 undergraduates studying an engineering course in an Australian university. Data analyses were conducted using cluster analyses, Hidden Markov Model, one-way ANOVAs, and a cross-tabulation. The relations between students' self-reported perceptions and their academic learning outcome show that those with positive perceptions tended to have higher scores. The relations between observational online learning behaviors and their academic learning outcome demonstrate that students with most learning sessions achieved more highly. The cross-tabulation finds a significant association between the cluster membership generated by by the self-reported perceptions and observational online learning behaviors. Amongst students who had most study sessions characterized by high percentages of reading and formative states and low percentage of summative states, the proportion of those with positive perceptions (40.2\%) was significantly higher than those with negative perceptions $(20.0 \%)$. Of students who had the least study sessions represented by moderate reading and summative states, and low formative states, the proportion of students with positive perceptions $(3.0 \%)$ was significantly lower than the proportion of students having negative perceptions $(8.7 \%)$.
\end{abstract}




\section{Introduction}

Learning analytics in higher education is used for a number of purposes, such as issues of attrition (Dawson, Jovanovic, Gašević, \& Pardo, 2017), social presence (Joksimović, Gašević, Kovanović, Riecke, \& Hatala, 2015), learning design (Tempelaar, Rienties, \& Giesbers, 2015), and education policy (Ferguson et al., 2016). While some learning analytic studies adopt bottom-up approaches, which are predominantly guided by empirical evidence separated from educational theories; others argue for top-down approaches, which sound theoretically orientated frameworks to guide the analyses of online analytic data (Gašević, Dawson, \& Siemens, 2015). In the extant literature, however, there is a dearth of research, which combines measures of analytics and the intent and experience of the students underpinning them (Han \& Ellis, 2017). To improve our understanding of student online learning experiences, it is important to investigate how the two approaches are associated with each other, and the extent to which the results derived from the two approaches are triangulated. This study uses top-down (i.e., students' self-reported perceptions of their online learning experience) and bottom-up approaches (i.e., the patterns of students' online learning behaviors) separately to investigate the relations between either students' self-reported and observational online learning experiences and their academic learning outcomes. It then examines the association of the patterns of online learning generated from the two.

Three research questions guided the present study:

1. What are the relations between students' self-reported perceptions of online learning environment and their academic learning outcomes?

2. What are the relations between students' observational online learning behaviors and their academic learning outcomes?

3. To what extent are the patterns of self-reported perceptions of online learning environment and their online learning behaviors associated?

\section{Method}

\section{Participants}

The participants of the study were 319 volunteers, who studied towards a Bachelor of Engineering degree in an Australian university. The course required students to attend lectures, tutorials, and laboratory practice sessions each week and compulsory participation in the online learning.

\section{Instruments and data}

\section{Self-reported data}

We used a 5-point Likert questionnaire to examine students' self-reported perceptions of online learning environment. The questionnaire consisted of two scales: 1) perceptions of integrated learning environment, which assessed the extent of how online part of learning is integrated with the whole course ( 7 items, $\alpha=.86$ ); and 2 ) perceptions of online contributions, which examined the extent of how students valued online contributions by themselves and by their classmates ( 6 items, $\alpha=.87$ ).

2 Open/Technology in Education, Society, and Scholarship Association Conference Proceedings: 2021, Vol. 1(1) 1-6 


\section{Observational Data}

We obtained the learning analytic data of students' online learning behaviors in week two to five from the LMS (we excluded the data from week 1 because this week was given to students for them to make decision as to if they were going to enrol in this course). There were five types of online learning behaviors: reading printed learning materials, watching video learning materials, solving problems in sequences (formative learning), self-testing key concepts in the course (summative learning), and viewing feedback and progression of online learning.

\section{Academic Learning Outcome}

We used the scores of the mid-term examination as an indicator of students' academic learning outcome. The mid-term examination consisted of a set of 20 multiple-choice problem-solving questions on the topics covered in the first 5 weeks of the course.

\section{Data Analysis}

The participants of the study were 319 volunteers, who studied towards a Bachelor of Engineering degree in an Australian university. The course required students to attend lectures, tutorials, and laboratory practice sessions each week and compulsory participation in the online learning.

\section{Results}

\section{Students' Self-Reported Perceptions of Online Learning Environment and Their Academic Learning Outcomes}

The results of the cluster analysis and one-way ANOVAs are displayed in Table 1.

\section{Table 1}

Results of cluster analysis and one-way ANOVAs of the self-reported data

\begin{tabular}{lccccc}
\hline variable & $\begin{array}{c}\text { positive perceptions } \\
(N=169)\end{array}$ & $\begin{array}{c}\text { negative perceptions } \\
(N=150)\end{array}$ & & $p$ & $\eta^{2}$ \\
& $M$ & $M$ & & & \\
\hline INTER & .52 & -.59 & 96.90 & .00 & .30 \\
OC & .39 & -.46 & 67.16 & .00 & .18 \\
ALO & .47 & -.59 & 88.97 & .00 & .29 \\
\hline
\end{tabular}

\section{Students' Observed Online Learning Behaviors}

The Hidden Markov Model (HMM) identified three study session states: reading state (in green): predominantly reading behaviors and few metacognitive behaviors; formative state (in light blue): predominantly formative learning behaviors, few watching video and reading behaviors; summative state (in dark blue): predominantly summative learning behaviors, few reading and metacognitive behaviors. The agglomerative hierarchical clustering analysis, which used the above identified three states, generated four HMM clusters visualized in Figure 1. 


\section{Figure 1}

The Four HMM Clusters

HMM cluster $1(N=98)$

State dist. - cl: 1

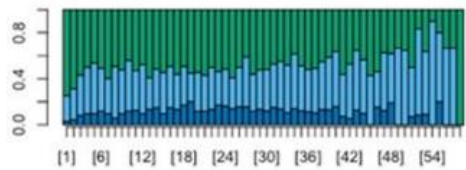

HMM cluster $3(N=18)$

State dist. - cl: 3

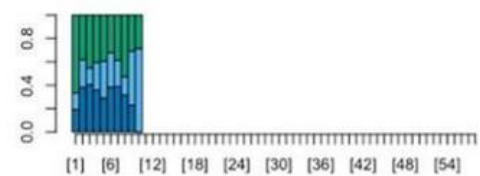

HMM cluster $2(N=143)$

State dist. - cl: 2

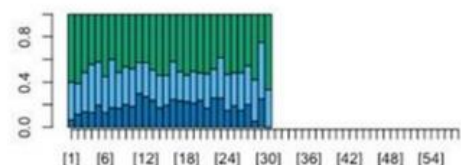

HMM cluster $4(N=60)$

State dist. - cl: 4

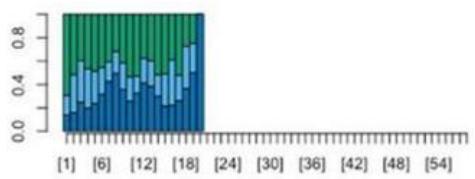

HMM cluster 1 ( $\mathrm{N}=98)$ : most study sessions with high percentages of reading and formative states and low percentage of summative states.

HMM cluster $2(\mathrm{~N}=143)$ : the second most study sessions with high percentage of reading states, moderate percentage of formative states, and low percentage of summative states.

HMM cluster $3(\mathrm{~N}=18)$ : the least study sessions with moderate reading and summative states, and low formative states.

HMM cluster $4(\mathrm{~N}=60)$ : the second least study sessions with high percentage of reading states, moderate percentage of summative states, and low percentage of formative states.

The results of the one-way ANOVA in Table 2 of the academic learning outcome showed that there were significant differences amongst the four $\operatorname{HMM}$ clusters: $F(3,316)=7.43, p<.01, \eta^{2}$ $=.07$.

\section{Table 2}

Results of Post-Hoc Analyses of the Academic Learning Outcome by HMM Clusters

\begin{tabular}{llll}
\hline HMM cluster & $M$ & $S D$ & post-hoc \\
\hline HMM cluster 1 & 14.36 & 3.36 & $1>2$ \\
& & $1>3$ \\
& & $1>4$ \\
\hline HMM cluster 2 & 13.13 & 3.56 & $2<1$ \\
& & $2>3$ \\
HMM cluster 3 & & $2=4$ \\
& 10.94 & 2.60 & $3<1$ \\
& & $3<2$ \\
HMM cluster 4 & & $3=4$ \\
\hline & 12.45 & 3.22 & $4<1$ \\
& & $4=2$ \\
\hline
\end{tabular}




\section{Association Between Self-Reported Perceptions of Online Learning Environment and Observational Online Learning Behaviors}

The cross-tabulation results in Table 3 show that there was a significant association between cluster membership generated by the self-reported perceptions and observational online learning behaviors, $X^{2}(3)=20.56, p<.01$.

\section{Table 3}

Results of Cross-Tabulation

\begin{tabular}{lllll}
\hline HMM cluster & count & positive & negative & total \\
& $\%$ & & & \\
\hline HMM cluster 1 & count & $68_{\mathrm{a}}$ & $30_{\mathrm{b}}$ & 98 \\
& $\%$ within perceptions & $40.2 \%$ & $20.0 \%$ & $30.7 \%$ \\
\hline HMM cluster 2 & count & $73_{\mathrm{a}}$ & $70_{\mathrm{a}}$ & 143 \\
& $\%$ within perceptions & $43.2 \%$ & $46.7 \%$ & $44.8 \%$ \\
\hline HMM cluster 3 & count & $5 \mathrm{a}$ & $13 \mathrm{~b}$ & 18 \\
& $\%$ within perceptions & $3.0 \%$ & $8.7 \%$ & $5.6 \%$ \\
\hline HMM cluster 4 & count & $23 \mathrm{a}$ & $37 \mathrm{~b}$ & 60 \\
& $\%$ within perceptions & $13.6 \%$ & $24.7 \%$ & $18.8 \%$ \\
\hline total & count & 169 & 150 & 319 \\
& $\%$ within perceptions & $100.0 \%$ & $100.0 \%$ & $100.0 \%$ \\
\hline
\end{tabular}

\section{Conclusions}

The combined approaches and multiple data sources from self-reported survey and digital traces recorded in the LMS demonstrate the triangulation between the two, which improves the quality of the analyses over a single data source.

\section{Author's Contributions}

F.H. conceived and designed research; performed experiments; analyzed data and interpreted results of experiments; drafted manuscript; edited and revised manuscript; F.H. and approved final version of manuscript.

\section{Open Researcher and Contributor Identifier (ORCID)}

Feifei Han (iD https://orcid.org/0000-0001-8464-0854

\section{Funding}

No funding is received for the study.

\section{Ethics Statement}

The study was approved by the Human Research Ethics Committee of the researchers'

University. 


\section{Conflict of Interest}

The authors do not declare any conflict of interest.

\section{Data Availability Statement}

The datasets generated and analysed during the current study are not publicly available due to ethics requirement, but are available from the corresponding author on reasonable request.

\section{References}

Dawson, S., Jovanovic, J., Gašević, D., \& Pardo, A. (2017, March). From prediction to impact: Evaluation of a learning analytics retention program. In Proceedings of the Seventh International Learning Analytics \& Knowledge Conference (pp. 474-478). ACM.

Ferguson, R., Brasher, A., Clow, D., Cooper, A., Hillaire, G., Mittelmeier, J., \& Rienties, B. (2016). Research evidence on the use of learning analytics. JRC Science for Policy Report.

Han, F., \& Ellis, R. (2017). Variations in coherence and engagement in students' experience of blended learning. In $\mathrm{H}$. Partridge, K. Davis, \& J. Thomas. (Eds.), Me, Us, IT! Proceedings ASCILITE2017: 34th International Conference on Innovation, Practice and Research in the Use of Educational Technologies in Tertiary Education (pp. 268-275). Toowoomba: University of Southern Queensland.

Gašević, D., Dawson, S., \& Siemens, G. (2015). Let's not forget: Learning analytics are about learning. TechTrends, 59(1), 64-71.

Joksimović, S., Gašević, D., Kovanović, V., Riecke, B. E., \& Hatala, M. (2015). Social presence in online discussions as a process predictor of academic performance. Journal of Computer Assisted Learning, 31(6), 638-654.

Tempelaar, D. T., Rienties, B., \& Giesbers, B. (2015). In search for the most informative data for feedback generation: Learning Analytics in a data-rich context. Computers in Human Behavior, 47, 157-167. 